Research Paper

\title{
Prognostic value of serological markers of hepatitis $B$ virus infection in squamous cell cervical cancer
}

\author{
Xingrao $\mathrm{Wu}^{1^{*}}$, Lan $\mathrm{Li}^{1^{*}}$, Yanqing $\mathrm{Li}^{*}$, Meiping Jiang ${ }^{1}$, Kangming $\mathrm{Li}^{1}$, Zheng $\mathrm{Li}^{2}$ and Lan Zhang ${ }^{\bowtie}$ \\ 1. Department of Radiation Oncology, Yunnan Cancer Hospital, The Third Affiliated Hospital of Kunming Medical University, Yunnan Cancer Center, No. \\ 519, Kunzhou Road, Kunming 650118, People's Republic of China. \\ 2. Department of Gynecologic Oncology, Yunnan Cancer Hospital, The Third Affiliated Hospital of Kunming Medical University, Yunnan Cancer Center, No. \\ 519, Kunzhou Road, Kunming 650118, People's Republic of China. \\ *These authors contributed equally to this article. \\ $\square$ Corresponding author: Dr. Lan Zhang, M.D., Ph.D., No. 519, Kunzhou Road, Kunming 650118, People’s Republic of China. E-mail: zhanglan@kmmu.edu.cn. \\ () The author(s). This is an open access article distributed under the terms of the Creative Commons Attribution License (https://creativecommons.org/licenses/by/4.0/). \\ See http://ivyspring.com/terms for full terms and conditions.
}

Received: 2021.04.04; Accepted: 2021.08.23; Published: 2021.09.13

\begin{abstract}
Objective: The current study aimed to investigate the prognostic value of serological markers of hepatitis $B$ virus (HBV) infection in squamous cell cervical cancer.

Methods: Squamous cell cervical cancer patients treated by concurrent chemoradiotherapy from January 2013 to December 2015 at Yunnan Cancer Hospital were retrospectively reviewed.

Results: Of a total of 277 patients, 12 (4.33\%), 93 (33.57\%), 2 (0.72\%), 25 (9.02\%), and 36 patients $(13.00 \%)$ were seropositive for hepatitis $B$ surface antigen $(\mathrm{HBs} A g)$, anti-hepatitis $B$ surface antibodies (anti-HBs), hepatitis $B$ envelope antigen ( $\mathrm{HBeAg}$ ), anti-hepatitis $B$ envelope antibodies (anti-HBe), and anti-hepatitis B core antibodies (anti-HBc), respectively. No patients experienced more than mild hepatic adverse events during treatment. The five-year overall survival $(O S)$ rates for patients with anti-HBs positive or negative status were $85.8 \%$ and $66.2 \%(p=0.039)$, respectively. No statistically significant difference in the five-year OS rates was observed in $\mathrm{HBsAg}$ positive and negative, $\mathrm{HBeAg}$ positive and negative, anti-HBe positive and negative, anti-HBc positive and negative patients. The multivariable analysis revealed that anti-HBs positivity was an independent favorable prognostic factor for OS (HR= $0.279 ; 95 \% \mathrm{Cl}: 0.083-0.936 ; p=0.039$ ) in patients younger than 50 years.
\end{abstract}

Conclusions: The presence of anti-HBs predicts a superior OS for squamous cell cervical cancer patients aged younger than 50 years.

Key words: cervical cancer; hepatitis B virus; serologic markers; prognosis

\section{Introduction}

Cervical cancer is a leading cause of cancerrelated morbidity and mortality among women in developing countries. Despite advances in diagnostic and screening techniques and a wider availability of vaccines, a significant proportion of patients are diagnosed with local advanced disease at the initial visit [1]. For the majority of patients who present with squamous cell carcinoma, concurrent chemoradiotherapy is the primary treatment modality for local advanced disease [2]. The International Federation of Gynecology and Obstetrics (FIGO) staging system is a reliable method for determining clinical treatment strategies and predicting treatment outcome [2]; however, additional prognostic factors are required to improve outcome prediction and tailor individualized treatment for patients with cervical cancer $[3,4]$.

$\mathrm{HBV}$ infection represents the most comment chronic viral infection in the world. Approximately $30 \%$ of the world's population exhibits serological evidence of a current or previous HBV infection [5]. In addition, HBV infection is associated with an increased risk of both hepatocellular carcinoma and extra-hepatic malignancies [6-11]. Moreover, HBV infection has been found to be associated with the prognosis of malignancies. Current or past HBV infection was shown to be an adverse prognostic 
factor in patients with nasopharyngeal carcinoma [12], lung cancer [13], breast cancer [14], ovarian cancer [15], diffuse large B cell lymphoma [16-18], and pancreatic cancer [19]. The latent mechanism leading to the unfavorable prognosis in $\mathrm{HBV}$-infected patients with malignancies may be linked to certain types of immunological dysfunction [20], HBV reaction [21] or the presence of Hepatitis B X-interacting protein, which plays an oncogenic role in cancer progression [22]. Given that HBV can be transmitted by sexual contact, it is plausible that HBV may interact with human papillomavirus to promote the development and progression of cervical cancer. However, whether and to what extent HBV infection impacts clinicopathological characteristics and prognosis of cervical cancer remains to be determined.

The great majority of previous studies considered hepatitis B surface antigen (HBsAg) as marker of $\mathrm{HBV}$ infection. Less attention has been paid to the role of other HBV-related antibodies and antigens, including antibody to hepatitis B surface antigen (anti-HBs), a protective body in $\mathrm{HBV}$ infection, hepatitis B e antigen ( $\mathrm{HBeAg})$, hepatitis B envelope antibody (anti-HBe), antibody to hepatitis B core antigen (anti-HBc), the marker of past exposure to HBV on patient survival. In this study, we aimed to evaluate the different baseline serological markers of $\mathrm{HBV}$ infection with cervical cancer survival in a region where both $\mathrm{HBV}$ and cervical cancer are endemic.

\section{Methods}

\section{Ethical considerations}

This retrospective study was approved by the Research Ethical Committees of the Third Affiliated Hospital of Kunming Medical University (Kunming, China). Informed consent was waived by the committee due to the retrospective nature of this study. The confidentiality of the patient status was maintained by avoiding personal identifiers during analysis.

\section{Patient Selection}

Squamous cell cervical cancer patients who received radical radiotherapy were consecutively recruited from January 2013 to December 2015. All patients were selected according to the clinical information extracted from the Electronic Medical Record (EMR) system. The inclusion criteria were as follows: (1) confirmed histological diagnosis of cervical squamous cell cancer; (2) completion of concurrent chemoradiotherapy with definitive-intent; (3) serological markers of $\mathrm{HBV}$ infection, including HBsAg, anti-HBs, HBeAg, anti-HBe, anti-HBc before treatment; (4) $\geq 20$ and $\leq 70$ years old; (5) Easter
Cooperative Oncology Group (ECOG) $\leq 1$. Patients were excluded if they met the following criteria: (1) had previously received any anticancer therapy; (2) coinfection with hepatitis $\mathrm{C}$ virus (HCV) and/or human immunodeficiency virus (HIV), or with an unknown HCV or HIV status; (3) a history of previous or synchronous malignant tumors; (4) pregnant of lactating; and (5) unsuitable for chemotherapy due to a liver, kidney, lung, or heart deficiency. Diagnoses of cervical squamous cell cancer were based on the comprehensive cervical cancer control guidelines of the World Health Organization (WHO). Cancers were staged by two experienced gynecologic oncologists based on a vaginal examination, chest and abdomen computed tomography (CT) with iodine-containing contrast medium, and pelvic magnetic resonance imaging (MRI), or positron emission tomography-CT (PET-CT) according to the FIGO 2009 standard. Lymph nodes with a short-axis diameter over $10 \mathrm{~mm}$ or relative apparent diffusion coefficient (ADC) values in imaging studies, or image findings of ring enhancement and marked necrosis, were defined as lymphadenopathy.

\section{Treatment}

All patients were treated with definitive-intent concurrent chemoradiotherapy. Most patients (130 of $277 ; 46.9 \%)$ were treated with 2-dimensional conventional radiotherapy (2-DRT), whereas $42.6 \%$ (118 of 277) received intensity-modulated radiotherapy (IMRT), and the remaining 10.5\% (29 of 277) received 3-dimensional conformal radiotherapy (3-DCRT). Patients received 45 Gy - 50.4 Gy external beam radiotherapy delivered to the pelvis in 23-28 fractions of $1.8 \mathrm{~Gy}-2.0 \mathrm{~Gy}$, with concurrent weekly cisplatin/nedaplatin chemotherapy at a dose of 25 $\mathrm{mg} / \mathrm{m}^{2}-40 \mathrm{mg} / \mathrm{m}^{2}$ for four to six cycles, and high dose rate intracavity brachytherapy of 20 Gy - 30 Gy in 4-5 fractions beginning at week five of external radiotherapy.

\section{Virological measurements and liver function studies}

Patients were screened for serological HBsAg, anti-HBs, HBeAg, anti-HBe, and anti-HBc using enzyme-linked immunosorbent assay (WANTAI BioPharm, Beijing, China) at the time of diagnosis at Yunnan Cancer Hospital. Patients were also tested for the presence of antibodies specific for serum HIV, hepatitis A virus, HCV, hepatitis $\mathrm{D}$ virus, and hepatitis E virus using enzyme-linked immunosorbent assay (WANTAI BioPharm, Beijing, China). The cut-off values for the different hepatitis $B$ markers were set according to their average values of the negative control samples provided by the 
manufacturer of each commercial kit. The quality control for the measurement of the hepatitis B markers was performed in accordance with the manufacturer's protocols. Briefly, the test results for all positive and negative quality control samples were required to be correctly classified as indicated in each kit. Inconsistent results for quality control samples prompted repeated testing. In addition, a routine external quality assessment with the pooled serum provided by the Ministry of Health of the People's Republic of China was conducted daily. Specific workers were responsible for sending blood samples for tests in time to guarantee the quality of the test. In most cases, the tests were only performed as a qualitative detection. HBV deoxyribonucleic acid (HBV-DNA) was not routinely detected.

All patients were monitored using routine liver function tests, including analyses of AST, ALT, and the total bilirubin levels every week during treatment. The severity of hepatic dysfunction and adverse events were defined according to the National Cancer Institute Common Toxicity Criteria (version 4.0).

\section{Follow-up}

After primary treatment, the patients were advised to receive regular follow-ups every three months for the first two years, every six months for the following three years, and annually thereafter. Patients who did not visit our hospital as scheduled were telephoned for follow-up to obtain the patient's status. The final follow-up occurred in January 2019. In the event of patient death, families were questioned about the cause of death. Overall survival (OS) was the primary endpoint that was evaluated, which was calculated from the first day of diagnosis to death or to the date of the last follow-up.

\section{Statistical analysis}

SPSS software (version 17.0, SPSS Inc., Chicago, IL) was used for all statistical analyses. Categorical variables in each of the different groups were compared using a chi-squared test or a Fisher's exact test, where indicated. Actuarial rates were calculated using the Kaplan-Meier method, and differences were compared using a log-rank test. A Cox regression was used for the univariate and multivariate analyses. Hazard ratios (HR) with their 95\% confidence intervals (CI) were computed using the Cox proportional-hazards model. Covariates, including host factors (i.e., age and hemoglobin), tumor factors (i.e., tumor size, differentiation, and lymph node status), and radiotherapy techniques were included in all tests. The threshold for statistical significance was set an a of 0.05 and all $p$ values were based on two-sided tests.

\section{Results}

\section{Baseline Patient Characteristics}

A total of 277 cases qualified for the analysis. All of the patients were from Southwestern China and were primarily distributed in the provinces of Yunnan and Guizhou. Of the 277 total patients, there were 12 patients (4.33\%) who were seropositive for HBsAg, 93 patients $(33.57 \%)$ seropositive for anti-HBs, 2 patients $(0.72 \%)$ seropositive for $\mathrm{HBeAg}, 25$ patients $(9.02 \%)$ seropositive for anti-HBe, and 36 patients $(13 \%)$ seropositive for anti-HBc. Table 1 summarizes the characteristics of these patients and their tumors. The HBsAg positive and negative groups were similar regarding host factors, histological categories, and tumor factors, as were the anti-HBs positive and negative groups, HBeAg positive and negative groups, anti-HBe positive and negative groups, and anti-HBc positive and negative groups (Table 2). There were no significant differences regarding the use of radiotherapy techniques between these groups (Table 2).

\section{Hepatic Adverse Events}

According to the liver enzyme and total bilirubin levels, no patients experienced moderate, severe, or life-threatening hepatic adverse events during concurrent chemoradiotherapy. However, we were unable to reliably ascertain hepatic adverse events that occurred after treatment completion since several patients received subsequent follow-up care at local facilities.

\section{Follow-up of Study Participants}

The median follow-up period for the 277-patient cohort was 44 months, with a maximum follow-up duration of 72 months. It is important to note that two types of follow-up were employed in this study. One group of patients underwent physical and/or imaging examinations for recurrent disease as scheduled. In contrast, the other group of patients did not return for examination. The survival of patients who did not return for examination were confirmed through telephone contact, and the precise onset of disease recurrence is unknown. Overall, as of the last day of follow-up, 204 patients $(73.65 \%)$ were alive with tumor-free or stable disease, 60 patients $(21.66 \%)$ died, and 13 patients $(4.69 \%)$ were lost to follow-up. The death of one patient $(1.67 \%)$ was attributed to a traffic accident; however, the patient was also diagnosed with cancer locoregional recurrence and distant metastasis. All of the other deaths were attributed to cancer $(98.33 \%)$. 
Table 1. Clinical characteristics

\begin{tabular}{|c|c|c|}
\hline Characteristics & All Patients (N=277) & No. $(\%)$ \\
\hline \multicolumn{3}{|l|}{ Age, years } \\
\hline$<50$ & 128 & 46.2 \\
\hline$\geq 50$ & 149 & 53.8 \\
\hline \multicolumn{3}{|l|}{ FIGO stage } \\
\hline I-II & 195 & 70.4 \\
\hline III-IV & 82 & 29.6 \\
\hline \multicolumn{3}{|l|}{ Tumor size (cm) } \\
\hline$<4$ & 68 & 24.5 \\
\hline$\geq 4$ & 209 & 75.5 \\
\hline \multicolumn{3}{|l|}{ Histological differentiation } \\
\hline Well and moderate & 182 & 65.7 \\
\hline Poor & 70 & 25.3 \\
\hline Papillary squamous carcinoma & 25 & 9.0 \\
\hline \multicolumn{3}{|l|}{ Lymphadenopathy } \\
\hline No & 151 & 54.5 \\
\hline Yes & 126 & 45.5 \\
\hline \multicolumn{3}{|l|}{ Hemoglobin $(\mathrm{g} / \mathrm{L})$} \\
\hline$<120$ & 84 & 30.3 \\
\hline$\geq 120$ & 193 & 69.7 \\
\hline \multicolumn{3}{|l|}{ Radiotherapy techniques } \\
\hline 2-DRT & 130 & 46.9 \\
\hline 3-DCRT & 29 & 10.5 \\
\hline IMRT & 118 & 42.6 \\
\hline \multicolumn{3}{|l|}{ HBsAg } \\
\hline Negative & 265 & 95.7 \\
\hline Positive & 12 & 4.3 \\
\hline \multicolumn{3}{|l|}{ Anti-HBs } \\
\hline Negative & 184 & 66.4 \\
\hline Positive & 93 & 33.6 \\
\hline \multicolumn{3}{|l|}{ HBeAg } \\
\hline Negative & 275 & 99.3 \\
\hline Positive & 2 & 0.7 \\
\hline \multicolumn{3}{|l|}{ Anti-HBe } \\
\hline Negative & 252 & 91.0 \\
\hline Positive & 25 & 9.0 \\
\hline \multicolumn{3}{|l|}{ Anti-HBc } \\
\hline Negative & 241 & 87.0 \\
\hline Positive & 36 & 13.0 \\
\hline
\end{tabular}

\section{Prognostic value of serological markers of HBV infection in cervical cancer patients}

We hypothesized that there may be a prognostic value of the baseline serological HBV markers on survival outcome. The Kaplan-Meier analysis and log-rank test showed no statistically significant differences in the five-year OS rates between HBsAg positive and negative patients $(76.0 \%$ vs $72.1 \%$; $p=$ 0.682) (Fig. 1A). The five-year OS rate of the anti-HBs positive patients was significantly higher than that of the anti-HBs negative patients $(85.8 \%$ vs $66.2 \%$; $p=$ 0.039) (Fig. 1B). The baseline HBeAg status was not associated with changes in the five-year OS $(p=0.155$; Fig. 1C). No statistically significant differences were observed for the five-year OS rates between the anti-HBe positive and negative groups $(78.8 \%$ vs $70.9 \% ; p=0.973$ ) (Fig. 1D), and the anti-HBc positive and negative groups $(69.9 \%$ vs $71.7 \% ; p=0.985)$ (Fig. $1 \mathrm{E})$.

In the univariate analysis, patients with cervical cancer who were anti-HBs positive had significantly superior OS compared with the anti-HBs negative patients $(\mathrm{HR}=0.530 ; 95 \% \mathrm{CI}, 0.287-0.980 ; p=0.043$ ) (Table 3). In the multivariate analysis, after adjusting for risk factors, including clinical stage, tumor size, histological differentiation, lymph node status, and hemoglobin, anti-HBs was not found to be an independent prognostic factor for OS $(\mathrm{HR}=0.788$; 95\% CI: 0.578-1.074; $p=0.132$ ) (Table 3). The upper limit of the $95 \% \mathrm{CI}$ nearly reached 1, indicating that anti-HBs positivity may be a potential favorable prognostic factor for OS.
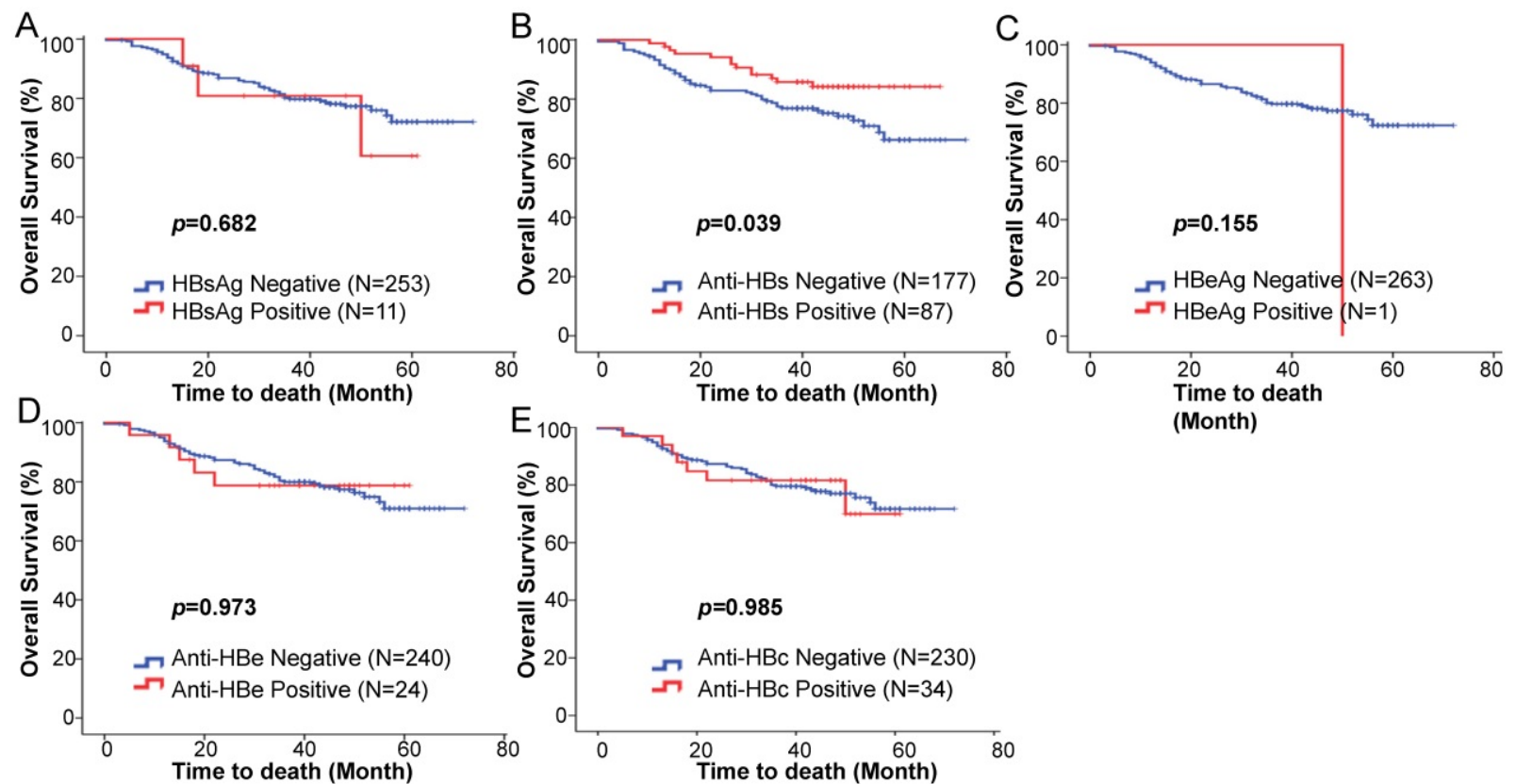

Figure 1. Kaplan-Meier estimated overall survival based on the $(\mathbf{A}) \mathrm{HBsAg}$, (B) anti-HBs, (C) $\mathrm{HBeAg}$, (D) anti-HBe, (E) anti-HBc status among squamous cell cervical cancer patients treated with concurrent chemoradiotherapy. 
Table 2. Relationships between HBV serological markers and patient characteristics

\begin{tabular}{|c|c|c|c|c|c|c|c|c|c|c|c|c|c|c|c|}
\hline Characteristics & $\frac{\text { HBsAg }}{(-)}$ & $\begin{array}{l}\text { HBsAg } \\
(+)\end{array}$ & $p$ & $\frac{\text { Anti-HBs }}{(-)}$ & $\begin{array}{l}\text { Anti-HBs } \\
(+)\end{array}$ & $p$ & $\frac{\text { HBeAg }}{(-)}$ & $\frac{\mathrm{HBeAg}}{(+)}$ & $p$ & $\frac{\text { Anti-HBe }}{(-)}$ & $\begin{array}{l}\text { Anti-HBe } \\
(+)\end{array}$ & $p$ & $\frac{\text { Anti-HBc }}{(-)}$ & $\begin{array}{l}\text { Anti-HBc } \\
(+)\end{array}$ & $p$ \\
\hline Age, years & & & 0.124 & & & 0.524 & & & 0.213 & & & 0.837 & & & 0.474 \\
\hline$<50$ & 120 & 8 & & 88 & 40 & & 126 & 2 & & 117 & 11 & & 109 & 19 & \\
\hline$\geq 50$ & 145 & 4 & & 96 & 53 & & 149 & 0 & & 135 & 14 & & 132 & 17 & \\
\hline FIGO stage & & & 0.772 & & & 0.481 & & & 0.505 & & & 0.854 & & & 0.893 \\
\hline I-II & 187 & 8 & & 127 & 68 & & 194 & 1 & & 177 & 18 & & 170 & 25 & \\
\hline III-IV & 78 & 4 & & 57 & 25 & & 81 & 1 & & 75 & 7 & & 71 & 11 & \\
\hline Tumor size (cm) & & & 0.182 & & & 0.126 & & & 0.418 & & & 0.674 & & & 0.728 \\
\hline$<4$ & 67 & 1 & & 40 & 28 & & 68 & 0 & & 61 & 7 & & 60 & 8 & \\
\hline$\geq 4$ & 198 & 11 & & 144 & 65 & & 207 & 2 & & 191 & 18 & & 181 & 28 & \\
\hline Histological differentiation & & & 0.764 & & & 0.186 & & & 0.591 & & & 0.204 & & & \\
\hline Well and moderate & 173 & 9 & & 118 & 64 & & 180 & 2 & & 169 & 13 & & 159 & 23 & 0.598 \\
\hline Poor & 68 & 2 & & 52 & 18 & & 70 & 0 & & 60 & 10 & & 59 & 11 & \\
\hline Papillary squamous carcinoma & 24 & 1 & & 14 & 11 & & 25 & 0 & & 23 & 2 & & 23 & 2 & \\
\hline Lymphadenopathy & & & 0.786 & & & 0.491 & & & 1 & & & 0.876 & & & 0.394 \\
\hline No & 144 & 7 & & 103 & 48 & & 150 & 1 & & 137 & 14 & & 129 & 22 & \\
\hline Yes & 121 & 5 & & 81 & 45 & & 125 & 1 & & 115 & 11 & & 112 & 14 & \\
\hline Hemoglobin $(\mathrm{g} / \mathrm{L})$ & & & 0.817 & & & 0.086 & & & 0.544 & & & 0.239 & & & 0.674 \\
\hline$<120$ & 80 & 4 & & 62 & 22 & & 83 & 1 & & 79 & 5 & & 72 & 12 & \\
\hline$\geq 120$ & 185 & 8 & & 122 & 71 & & 192 & 1 & & 173 & 20 & & 169 & 24 & \\
\hline Radiotherapy techniques & & & 0.765 & & & 0.539 & & & 0.887 & & & 0.819 & & & 0.742 \\
\hline 2-DRT & 125 & 5 & & 82 & 48 & & 129 & 1 & & 119 & 11 & & 113 & 17 & \\
\hline 3-DCRT & 27 & 2 & & 20 & 9 & & 29 & 0 & & 27 & 2 & & 24 & 5 & \\
\hline IMRT & 113 & 5 & & 82 & 36 & & 117 & 1 & & 106 & 12 & & 104 & 14 & \\
\hline
\end{tabular}

Abbreviations:(+), positive; $(-)$, negative; $\mathrm{HBsAg}$, hepatitis B surface antigen; anti-HBs, hepatitis B surface antibody; $\mathrm{HBeAg}$, hepatitis B envelope antigen; anti-HBe, hepatitis $\mathrm{B}$ envelope antibody; anti-HBc, hepatitis B core antibody; 2-DRT, 2-dimensional radiotherapy; 3-DRT,3-dimensional radiotherapy; IMRT, intensity-modulated radiotherapy; FIGO, International Federation of Gynecology and Obstetrics.

$p$ value was calculated using the chi-square test or Fisher exact test if indicated.

Table 3. Univariate and multivariate Cox hazards analysis between clinical features and OS

\begin{tabular}{|c|c|c|c|c|}
\hline \multirow[t]{2}{*}{ Characteristics } & \multicolumn{2}{|l|}{ Univariate analysis } & \multicolumn{2}{|l|}{ Multivariate analysis } \\
\hline & HR $(95 \% \mathrm{CI})$ & $p$-value & HR $(95 \% \mathrm{CI})$ & $p$-value \\
\hline \multicolumn{5}{|l|}{ Age, years } \\
\hline$\geq 50$ & 1 (Reference) & & & \\
\hline$<50$ & $1.113(0.668-1.854)$ & 0.682 & & \\
\hline \multicolumn{5}{|l|}{ FIGO stage } \\
\hline I-II & 1 (Reference) & & 1 (Reference) & \\
\hline III-IV & $2.100(1.258-3.504)$ & 0.006 & $1.665(0.968-2.863)$ & 0.065 \\
\hline \multicolumn{5}{|l|}{ Tumor size (cm) } \\
\hline$<4$ & 1 (Reference) & & 1 (Reference) & \\
\hline$\geq 4$ & $1.989(0.979-4.039)$ & 0.057 & $1.176(0.815-1.698)$ & 0.386 \\
\hline \multicolumn{5}{|c|}{ Histological differentiation } \\
\hline Well and moderate & 1 (Reference) & & 1(Reference) & \\
\hline $\begin{array}{l}\text { Papillary squamous } \\
\text { carcinoma }\end{array}$ & $0.425(0.102-1.766)$ & 0.239 & & \\
\hline Poor & $1.883(1.107-3.204)$ & 0.019 & $1.322(0.881-1.982)$ & 0.177 \\
\hline \multicolumn{5}{|l|}{ Lymphadenopathy } \\
\hline No & 1 (Reference) & & & \\
\hline Yes & $1.873(1.106-3.115)$ & 0.019 & 1.797 (1.071-3.017) & 0.027 \\
\hline \multicolumn{5}{|l|}{ Hemoglobin $(\mathrm{g} / \mathrm{L})$} \\
\hline$\geq 120$ & 1 (Reference) & & & \\
\hline$<120$ & $3.227(1.942-5.361)$ & $<0.001$ & $1.678(1.282-2.198)$ & $<0.001$ \\
\hline \multicolumn{5}{|l|}{ RT techniques } \\
\hline 2-DRT & 1 (Reference) & & & \\
\hline 3-DCRT & $0.925(0.357-2.398)$ & 0.872 & & \\
\hline IMRT & $1.100(0.647-1.868)$ & 0.725 & & \\
\hline \multicolumn{5}{|l|}{ Anti-HBs } \\
\hline Negative & 1 (Reference) & & 1 (Reference) & \\
\hline Positive & $0.530(0.287-0.980)$ & 0.043 & $0.788(0.578-1.074)$ & 0.132 \\
\hline $\begin{array}{l}\text { Abbreviations: } 95 \% \mathrm{C} \\
\text { Gynecology and Obst } \\
\text { 3-DRT,3-dimensional } \\
\text { anti-HBs, hepatitis B }\end{array}$ & $\begin{array}{l}95 \% \text { confidence inte } \\
\text { etrics; 2-DRT, 2-dime } \\
\text { radiotherapy; IMRT, } \\
\text { urface antibody; HR }\end{array}$ & $\begin{array}{l}\text { val; FIGO } \\
\text { sional ra } \\
\text { ntensity-1 }\end{array}$ & $\begin{array}{l}\text { International Feder } \\
\text { liotherapy; } \\
\text { nodulated radiother } \\
\text { io. }\end{array}$ & ation of \\
\hline
\end{tabular}

We further examined the prognostic value of anti-HBs in the different subgroups stratified according to age, clinical stage, tumor size, tumor differentiation, lymph node status, and hemoglobin. The effect of HBsAg differed significantly by patient age or lymph node status, with a favorable effect for patients aged younger than 50 years old $(\mathrm{HR}=0.269$; 95\%CI: 0.081-0.896; $p=0.039$; Table 4) and without lymphadenopathy ( $\mathrm{HR}=0.287 ; 95 \% \mathrm{CI}$ : 0.086-0.962; $p$ $=0.043$; Table 4). The five-year OS was significantly higher in the anti-HBs positive patients in the under 50 years subgroup $(90.9 \%$ vs $74.9 \% ; p=0.022$; Fig. 2 A) and without lymphadenopathy subgroup $(93.0 \%$ vs $79.3 \% ; p=0.031$; Fig. 2 C). This was not the case for the $\geq 50$ years old subgroup $(\mathrm{HR}=0.766 ; 95 \% \mathrm{CI}$ : $0.366-1.603 ; p=0.480$; Table 4$)(79.2 \%$ vs $73.6 \%$; $p=$ 0.477; Fig. 2B), with lymphadenopathy subgroup (HR $=0.711 ; 95 \%$ CI: 0.342-1.475; $p=0.359$; Table 4$)(75.0 \%$ vs $68.0 \% ; p=0.356$; Fig. $2 \mathrm{D}$ ). The effect of anti-HBs on patient survival was not significant in the subgroups stratified by clinical stage (Supplementary Fig. 1A), tumor size (Supplementary Fig. 1B), tumor differentiation (Supplementary Fig. 1C), and hemoglobin (Supplementary Fig. 1D) (Fig. 2). Among the patients aged younger than 50 years old, anti-HBs positivity was found to be an independent prognostic factor for superior OS (HR $=0.279$; 95\% CI: 0.083-0.936; $p=0.039$ ) (Table 5). 

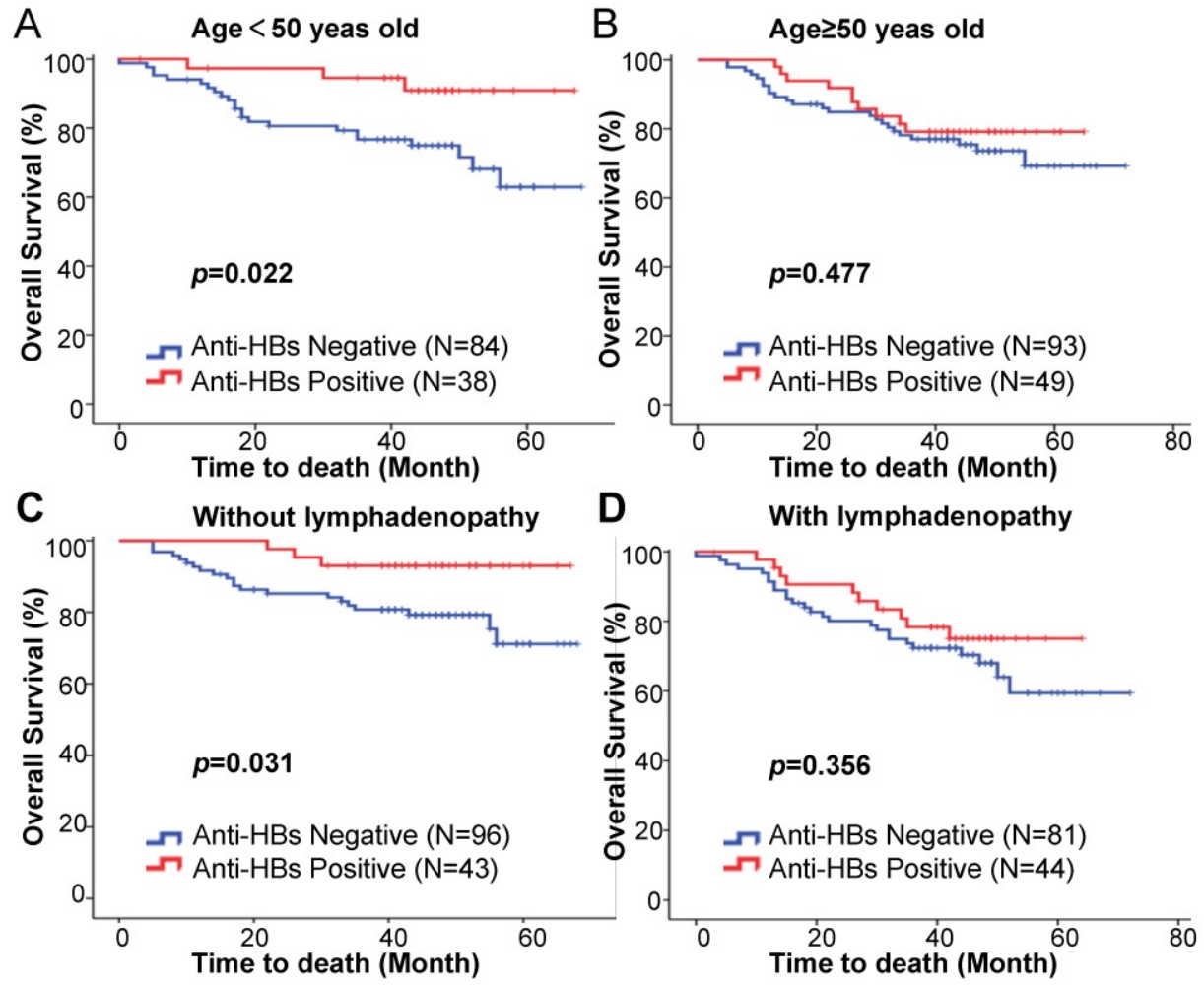

Figure 2. Kaplan-Meier estimation of overall survival based on the anti-HB status among patients $(\mathbf{A})$ aged $<50$ years, (B) aged $\geq 50$ years, $(\mathbf{C})$ without lymphadenopathy, and (D) with lymphadenopathy.

Table 4. Subgroup analysis by anti-HBs status for OS in squamous cell cervical cancer patients

\begin{tabular}{|c|c|c|c|}
\hline \multirow[t]{2}{*}{ Prognostic factor } & \multirow{2}{*}{$\frac{\text { OS (months) }}{\text { Mean }}$} & \multicolumn{2}{|l|}{ Effect estimate } \\
\hline & & $\mathrm{HR}(95 \% \mathrm{CI})$ & $p$-value \\
\hline \multicolumn{4}{|l|}{ Age (years) } \\
\hline$<50$ & & & 0.032 \\
\hline Anti-HBs negative & 53.7 & 1 (Reference) & \\
\hline Anti-HBs positive & 63.5 & $0.269(0.081-0.896)$ & \\
\hline$\geq 50$ & & & 0.48 \\
\hline Anti-HBs negative & 58.2 & 1 (Reference) & \\
\hline Anti-HBs positive & 56.5 & $0.766(0.366-1.603)$ & \\
\hline \multicolumn{4}{|l|}{ Lymphadenopathy } \\
\hline No & & & 0.043 \\
\hline Anti-HBs negative & 56.8 & 1 (Reference) & \\
\hline Anti-HBs positive & 64.1 & $0.287(0.086-0.962)$ & \\
\hline Yes & & & 0.359 \\
\hline Anti-HBs negative & 54.2 & 1 (Reference) & \\
\hline Anti-HBs positive & 54.4 & $0.711(0.342-1.475)$ & \\
\hline \multicolumn{4}{|l|}{ FIGO stage } \\
\hline I-II & & & 0.145 \\
\hline Anti-HBs negative & 56.9 & 1 (Reference) & \\
\hline Anti-HBs positive & 61.9 & $0.554(0.251-1.225)$ & \\
\hline III-IV & & & 0.235 \\
\hline Anti-HBs negative & 50.3 & 1 (Reference) & \\
\hline Anti-HBs positive & 53.6 & $0.554(0.208-1.470)$ & \\
\hline \multicolumn{4}{|l|}{ Tumor size (cm) } \\
\hline$<4$ & & & 0.66 \\
\hline Anti-HBs negative & 63 & 1 (Reference) & \\
\hline Anti-HBs positive & 60.8 & $0.732(0.183-2.931)$ & \\
\hline$\geq 4$ & & & 0.061 \\
\hline Anti-HBs negative & 53.1 & 1 (Reference) & \\
\hline Anti-HBs positive & 59.5 & $0.516(0.258-1.030)$ & \\
\hline \multicolumn{4}{|l|}{ Hemoglobin $(g / L)$} \\
\hline$<120$ & & & 0.276 \\
\hline Anti-HBs negative & 45.2 & 1 (Reference) & \\
\hline Anti-HBs positive & 51.8 & $0.611(0.251-1.485)$ & \\
\hline$\geq 120$ & & & 0.198 \\
\hline
\end{tabular}

\begin{tabular}{|c|c|c|c|}
\hline \multirow[t]{2}{*}{ Prognostic factor } & \multirow{2}{*}{$\frac{\text { OS (months) }}{\text { Mean }}$} & \multicolumn{2}{|l|}{ Effect estimate } \\
\hline & & HR $(95 \% \mathrm{CI})$ & $p$-value \\
\hline Anti-HBs negative & 62.3 & 1 (Reference) & \\
\hline Anti-HBs positive & 62.3 & $0.570(0.242-1.341)$ & \\
\hline \multicolumn{4}{|l|}{ Histological differentiation } \\
\hline Well and moderate & & & 0.283 \\
\hline Anti-HBs negative & 59.7 & 1 (Reference) & \\
\hline Anti-HBs positive & 60.5 & $0.671(0.323-1.391)$ & \\
\hline Poor & & & 0.39 \\
\hline Anti-HBs negative & 48.2 & 1 (Reference) & \\
\hline Anti-HBs positive & 44.8 & $0.584(0.172-1.987)$ & \\
\hline Papillary squamous carcinoma & & & 0.507 \\
\hline Anti-HBs negative & 40.5 & 1 (Reference) & \\
\hline Anti-HBs positive & 48.3 & $0.020(0.000-2089.644)$ & \\
\hline
\end{tabular}

\section{Discussion}

Although a vaccination subsidy was provided to cover all infants and subsequently led to a substantial reduction in the $\mathrm{HBV}$ infection rate among Chinese children, HBV infection remains highly prevalent in populations over 5 years of age [23]. HBV infection is associated with dysfunction. The association between HBV infection and poor prognosis is keeping demonstrated in a variety of cancers, including nasopharyngeal carcinoma [12], lung cancer [13], breast cancer [14], ovarian cancer [15], diffuse large B cell lymphoma [16-18], and pancreatic cancer patients [19]. We speculated HBV infection may have an impact on the prognosis of cervical cancer patients. 
Table 5. Multivariate analysis of prognostic factors for patients $<50$ years old

\begin{tabular}{|c|c|c|}
\hline \multirow[t]{2}{*}{ Characteristics } & \multicolumn{2}{|l|}{ Multivariate analysis } \\
\hline & $\mathrm{HR}(95 \% \mathrm{CI})$ & $p$-value \\
\hline FIGO stage & & 0.015 \\
\hline$\geq 50$ & 1 (Reference) & \\
\hline$<50$ & $2.808(1.220-6.461)$ & \\
\hline Tumor size (cm) & & 0.664 \\
\hline I-II & 1 (Reference) & \\
\hline III-IV & $1.135(0.641-2.012)$ & \\
\hline Histological differentiation & & 0.146 \\
\hline Well and moderate & 1 (Reference) & \\
\hline Poor & $1.559(0.857-2.834)$ & \\
\hline Lymphadenopathy & & 0.034 \\
\hline No & 1 (Reference) & \\
\hline Yes & 1.558 (1.004-2.342) & \\
\hline Hemoglobin $(\mathrm{g} / \mathrm{L})$ & & 0.007 \\
\hline$\geq 120$ & 1 (Reference) & \\
\hline$<120$ & $3.342(1.388-8.046)$ & \\
\hline Anti-HBs & & 0.039 \\
\hline Negative & 1 (Reference) & \\
\hline Positive & $0.279(0.083-0.936)$ & \\
\hline
\end{tabular}

HBV is a hepatotrophic and lymphotrophic virus that can infect and replicate in lymphocytes and peripheral blood mononuclear cells [24]. HBsAg is a serum marker of an ongoing HBV infection, including chronic hepatitis $\mathrm{B}$ and the inactive HBsAg carrier state. Theoretically, primary HBV infections spontaneously resolve in $95 \%$ of adults. However, in less than $10 \%$ of cases, the virus is contracted during the perinatal period, which can lead to persistent viral replication and chronic HBV infection (cases considered to be HBsAg positive). Anti-HBc is a serum marker for a current or previous $\mathrm{HBV}$ infection. Low levels of HBV replication in the serum or liver are considered to indicate a resolved HBV infection (HBsAg negative and anti-HBc positive) [25]. An HBV infection may increase susceptibility to chronic inflammation, DNA damage, and cancer development [26].

HBsAg or anti-HBc positivity have been demonstrated to be risk factors for extrahepatic cancers, such as gastric cancer [10], nasopharyngeal carcinoma [9], pancreatic cancer [26], biliary tract cancer [11], colorectal cancer, kidney cancer, ovarian cancer, and non-Hodgkin's lymphoma [12]. A few previous studies have assessed associations between HBV infection and cervical cancer. However, results of those studies were consistent. In a study by An et al. [27], cervical cancer was significantly related to HBV infection with a relative risk of $\sim 1.49$. Wei et al. [28] indicated cervical cancer might be HBV-related (adjusted odds ratio $=1.22 ; 95 \%$ CI: 1.05-1.42). The study of Siu et al. [29] found patients with malignant or pre-malignant cervical lesion have increased risk of becoming hepatitis B carrier. By contrast, non- significant association were observed between HBV infection and cervical cancer in other studies [6-8].The prevalence of $\mathrm{HBsAg}$ and anti-HBc positive patients with cervical cancer in this study were $4.3 \%$ (12 of 277) and $13.0 \%$ (36 of 277), respectively, lower than that of the general population in China $(7.2 \%$ and $34.1 \%$, respectively) [30]. Due to $\mathrm{HBsAg}$ positive patients with elevated baseline liver enzymes who did not complete concurrent chemotherapy were not included, the prevalence of HBsAg positive patients may be underestimated in this study. Whether HBV infection plays a role in cervical cancer development requires future population-based prospective studies or qualified case-control studies.

HBsAg positive patients with cancer, including nasopharyngeal carcinoma [12], lung cancer [13], breast cancer [14], ovarian cancer [15], diffuse large B cell lymphoma [16-18], and pancreatic cancer [19] have an inferior OS. Previous studies speculated that it may be linked to certain types of immunological dysfunction [20] HBV reactivation [21], or the presence of Hepatitis B X-interacting protein [22]. Given that HBV can be transmitted by sexual contact, it is plausible that HBV may be present in the epithelium of the cervix and promote the progression of cervical cancer. Subsequent systemic chronic inflammation and the altered cytokine network following HBV infection might also be relevant in cervical cancer progression. However, there were no significant association between HBsAg status and OS in cervical cancer patients in the present study. Interestingly, the anti-HBs positive cervical cancer patients had a significantly superior OS compared with the anti-HBs negative patients. Anti-HBs is a protective antibody in $\mathrm{HBV}$ infection. As suggested by the clinical value of anti-HBs, anti-HBs positivity may result from both an HBV infection or hepatitis B vaccination. We considered that the positive effect of anti-HBs may actually reflect the negative effect of HBV infection. Occult HBV infection has been described in patients negative for HBsAg who have been previously exposed to HBV and recovered from acute or chronic infection [31, 32]. After HBsAg disappearing, the systemic inflammation and HBV DNA may still persist in the body of the previous infection individuals and forced the body to react abnormally [25, 33]. Using HBsAg positive as an HBV infection indicator may omit the occult infection. Anti-HBs, which indicates the immunity of HBV, may potentially be of more clinical importance to be a predictor of patient survival than HBsAg.

However, why the prognostic impact of anti-HBs was not statistically significant for the total patients but was significant for patients younger than 50 years old remains unclear. It is reported the median ages at 
diagnosis and death of HBsAg positive cancer patients were significantly younger than those with HBsAg negative [28]. Li et al. [14] reported HBV infection was an unfavorable prognostic predictor in very young patients. Le et al. [34] reported that HBsAg levels declined with age in HBV infected patients. The oncogenic role of HBV infection seems to be age-dependent. The younger the infection, the more obvious the impact in patient cancer progression. The positive effect of anti-HBs in patients younger than 50 years old may be results of the negative effect of HBV infection. Future studies are warranted to elucidate the legitimacy and detailed mechanisms associated with the role of anti-HBs in cervical cancer.

Our study nevertheless has certain limitations. First, this was a retrospective study and has weak efficacy for testing prognostic factors that have a direct causal relationship. Secondly, the information regarding tumor control and relapse was incomplete, which restricted the analysis to disease free survival. Thirdly, due to a lack of data regarding the HBV DNA load, the survival of patients who exhibited a high HBV replication rate remains unknown. However, despite these limitations, our findings provide a rationale for further studies.

\section{Conclusion}

In conclusion, this study is the first to evaluate the prognostic value of serological markers of $\mathrm{HBV}$ infection in cervical cancer patients in China, where both diseases are endemic. Anti-HBs positivity was found to be an independent favorable prognostic factor in squamous cell cervical cancer patients aged younger than 50 years old and treated with concurrent chemoradiotherapy. Further prospective studies involving large cohorts of patients with cervical cancer are warranted to confirm these results. In addition, the latent mechanism by which anti-HBs is associated with a superior survival outcome in cervical cancer patients requires further investigation.

\section{Abbreviations}

OS: Overall survival; 2-DRT: 2-dimensional radiotherapy; 3-DRT: 3-dimensional radiotherapy; HBsAg: hepatitis B surface antigen; anti-HBs: hepatitis B surface antibody; HBeAg: hepatitis B envelope antigen; anti-HBe: hepatitis $B$ envelope antibody; anti-HBc: hepatitis B core antibody; IMRT: intensity-modulated radiotherapy; FIGO: International Federation of Gynecology and Obstetrics; ECOG: Easter Cooperative Oncology Group; HCV: hepatitis C virus; HIV: human immunodeficiency virus; WHO: World Health Organization; MRI: magnetic resonance imaging; PET-CT: positron emission tomography-computed tomography; ADC: apparent diffusion coefficient; DNA: deoxyribonucleic acid; HR: Hazard ratios; CI: confidence intervals; PD-1: programmed cell death protein; AST: aspartate aminotransferase; ALT: alanine aminotransferase; ULN: upper limit of normal.

\section{Supplementary Material}

Supplementary figure.

http://www.jcancer.org/v12p6620s1.pdf

\section{Acknowledgements}

The authors would like to thank the staff members of Yunnan Cancer Hospital Radiotherapy Center who treated and provided care for all cervical cancer patients.

\section{Funding}

This study was supported by the National Natural Science Foundation of China (81802614), the Open Funds of State Key Laboratory of Oncology in South China (HN2018-10), the Applied Basic Research Projects of Yunnan Province, China (2019FD090), the Joint Special Funds for the Department of Science and Technology of Yunnan Province-Kunming Medical University (2019FE001(-151)), Medical Reserve Personnel Training Plan of Yunnan Provincial Health Commission (H-2018003), and the Foundation of 100 Young and Middle-aged Academic and Technical Backbone of Kunming Medical University (6011826 0117).

\section{Ethics approval and consent to participate}

This study strictly conformed to the ethical guidelines of the Declaration of Helsinki and was approved by the Research Ethics Committee of the Third Affiliated Hospital of Kunming Medical University.

\section{Availability of data and materials}

The data used in this study are available from the corresponding author upon reasonable request.

\section{Author contributions}

Lan Zhang and Xingrao Wu conceived the study. Xingrao $\mathrm{Wu}$, Lan $\mathrm{Li}$, and Yanqing Li participated in the study design, case collection, drafting, and revisions of the manuscript. Meiping Jiang, Kangming $\mathrm{Li}$, and Zheng $\mathrm{Li}$ participated in data interpretation and manuscript revisions. All authors read and approved the final manuscript.

\section{Competing Interests}

The authors have declared that no competing interest exists. 


\section{References}

1. Chen W, Zheng R, Baade PD, Zhang S, Zeng H, Bray F, et al. Cancer statistics in China, 2015. CA Cancer J Clin. 2016; 66: 115-32.

2. Bhatla N, Aoki D, Sharma DN, Sankaranarayanan R. Cancer of the cervix uteri. Int J Gynaecol Obstet. 2018; 143 Suppl 2: 22-36.

3. Huang H, Liu Q, Zhu L, Zhang Y, Lu X, Wu Y, et al. Prognostic Value of Preoperative Systemic Immune-Inflammation Index in Patients with Cervical Cancer. Sci Rep. 2019; 9: 3284.

4. Lindegaard JC, Petric P, Lindegaard AM, Tanderup K, Fokdal LU. Evaluation of a New Prognostic Tumor Score in Locally Advanced Cervical Cancer Integrating Clinical Examination and Magnetic Resonance Imaging. Int J Radiat Oncol Biol Phys. 2020; 106: 754-63.

5. Trepo C, Chan HL, Lok A. Hepatitis B virus infection. Lancet. 2014; 384: 2053-63.

6. Kamiza AB, Su FH, Wang WC, Sung FC, Chang SN, Yeh CC. Chronic hepatitis infection is associated with extrahepatic cancer development: a nationwide population-based study in Taiwan. BMC Cancer. 2016; 16: 861.

7. Lu T, Yang Q, Li M, Zhang J, Zou J, Huang L, et al. HBV infection and extra-hepatic cancers in adolescents and 20s: A retrospective study in China. Cancer Epidemiol. 2018; 55: 149-55.

8. Mahale P, Engels EA, Koshiol J. Hepatitis B virus infection and the risk of cancer in the elderly US population. Int J Cancer. 2019; 144: 431-9.

9. Ye YF, Xiang YQ, Fang F, Gao R, Zhang LF, Xie SH, et al. Hepatitis B virus infection and risk of nasopharyngeal carcinoma in southern China. Cancer Epidemiol Biomarkers Prev. 2015; 24: 1766-73.

10. Wei XL, Qiu MZ, Jin Y, Huang YX, Wang RY, Chen WW, et al. Hepatitis B virus infection is associated with gastric cancer in China: an endemic area of both diseases. Br J Cancer. 2015; 112: 1283-90.

11. Hsing AW, Zhang M, Rashid A, McGlynn KA, Wang BS, Niwa S, et al. Hepatitis $B$ and $C$ virus infection and the risk of biliary tract cancer: a population-based study in China. Int J Cancer. 2008; 122: 1849-53.

12. Liu X, Li X, Jiang N, Lei $Y$, Tang LL, Chen $L$, et al. Prognostic value of chronic hepatitis $\mathrm{B}$ virus infection in patients with nasopharyngeal carcinoma: analysis of 1301 patients from an endemic area in China. Cancer. 2014; 120: 68-76.

13. Peng JW, Liu DY, Lin GN, Xiao JJ, Xia ZJ. Hepatitis B Virus Infection Is Associated with Poor Prognosis in Patients with Advanced Non Small Cell Lung Cancer. Asian Pac J Cancer Prev. 2015; 16: 5285-8.

14. Li N, Zhong QQ, Yang XR, Wang QC, Zhang DT, Zheng S, et al. Prognostic Value of Hepatitis B Virus Infection in Very Young Patients With Curatively Resected Breast Cancer: Analyses From an Endemic Area in China. Front Oncol. 2020; 10: 1403.

15. Wong L, Cheung TH, Yim SF, Lao TT. Prevalence and impact of hepatitis B virus infection in ovarian cancer patients in an endemic area-A retrospective cohort study. J Viral Hepat. 2020; 27: 520-5.

16. Al-Mansour MM, Alghamdi SA, Alsubaie MA, Alesa AA, Khan MA. Negative effect of hepatitis in overall and progression-free survival among patients with diffuse large B-cell lymphoma. Infect Agent Cancer. 2018; 13: 18.

17. Fang Y, Wang L, Qian Y, Zhao WL. [Efficacy and prognostic analysis of relapsed/refractory diffuse large B-cell lymphoma patients with hepatitis B virus infection]. Zhonghua Xue Ye Xue Za Zhi. 2018; 39: 1017-20.

18. Wang F, Xu RH, Luo HY, Zhang DS, Jiang WQ, Huang HQ, et al. Clinical and prognostic analysis of hepatitis B virus infection in diffuse large B-cell lymphoma. BMC Cancer. 2008; 8: 115.

19. Wei XL, Qiu MZ, Chen WW, Jin Y, Ren C, Wang F, et al. The status of HBV infection influences metastatic pattern and survival in Chinese patients with pancreatic cancer. J Transl Med. 2013; 11: 249.

20. Peng G, Li S, Wu W, Tan X, Chen Y, Chen Z. PD-1 upregulation is associated with HBV-specific $\mathrm{T}$ cell dysfunction in chronic hepatitis B patients. Mol Immunol. 2008; 45: 963-70.

21. Yeo W, Chan HL. Hepatitis B virus reactivation associated with anti-neoplastic therapy. J Gastroenterol Hepatol. 2013; 28: 31-7.

22. Xiu M, Zeng X, Shan R, Wen W, Li J, Wan R. The oncogenic role of HBXIP. Biomed Pharmacother. 2021; 133: 111045.

23. Yu R, Fan R, Hou J. Chronic hepatitis B virus infection: epidemiology, prevention, and treatment in China. Front Med. 2014; 8: 135-44.

24. Pontisso P, Vidalino L, Quarta S, Gatta A. Biological and clinical implications of HBV infection in peripheral blood mononuclear cells. Autoimmun Rev. 2008; 8: 13-7.

25. Yuki N, Nagaoka T, Yamashiro M, Mochizuki K, Kaneko A, Yamamoto K, et al. Long-term histologic and virologic outcomes of acute self-limited hepatitis B. Hepatology. 2003; 37: 1172-9.

26. Hassan MM, Li D, El-Deeb AS, Wolff RA, Bondy ML, Davila M, et al. Association between hepatitis B virus and pancreatic cancer. J Clin Oncol. 2008; 26: 4557-62.

27. An J, Kim JW, Shim JH, Han S, Yu CS, Choe J, et al. Chronic hepatitis B infection and non-hepatocellular cancers: A hospital registry-based, case-control study. PLoS One. 2018; 13: e0193232.

28. Wei XL, Luo HY, Li CF, Jin Y, Zeng ZL, Ju HQ, et al. Hepatitis B virus infection is associated with younger median age at diagnosis and death in cancers. Int $\mathrm{J}$ Cancer. 2017; 141: 152-9.

29. Siu SS, Cheung TH, Chan PK, Lin CK, Lo KW. Patients with malignant or pre-malignant cervical lesion have increased risk of becoming hepatitis $\mathrm{B}$ carrier. J Exp Clin Cancer Res. 2007; 26: 77-81.
30. Liang X, Bi S, Yang W, Wang L, Cui G, Cui F, et al. Reprint of: Epidemiological serosurvey of Hepatitis B in China--declining HBV prevalence due to Hepatitis B vaccination. Vaccine. 2013; 31 Suppl 9: J21-8.

31. Tamori A, Nishiguchi S, Kubo S, Narimatsu T, Habu D, Takeda T, et al. HBV DNA integration and HBV-transcript expression in non-B, non-C hepatocellular carcinoma in Japan. J Med Virol. 2003; 71: 492-8.

32. Kannangai R, Molmenti E, Arrazola L, Klein A, Choti M, Thomas DL, et al. Occult hepatitis B viral DNA in liver carcinomas from a region with a low prevalence of chronic hepatitis B infection. J Viral Hepat. 2004; 11: 297-301.

33. Michalak TI, Pardoe IU, Coffin CS, Churchill ND, Freake DS, Smith P, et al. Occult lifelong persistence of infectious hepadnavirus and residual liver inflammation in woodchucks convalescent from acute viral hepatitis. Hepatology. 1999; 29: 928-38.

34. Le Bert N, Gill US, Hong M, Kunasegaran K, Tan DZM, Ahmad R, et al. Effects of Hepatitis B Surface Antigen on Virus-Specific and Global T Cells in Patients With Chronic Hepatitis B Virus infection. Gastroenterology. 2020; 159: 652-64. 